\title{
Cooperative and Collaborative Knowledge Management, so how we should manage the most important resource of the organization - case study
}

\author{
Marta du Vall, ${ }^{1, *}$, Marta Majorek $^{1}$ \\ ${ }^{1}$ Andrzej Frycz Modrzewski Krakow University, Poland
}

\begin{abstract}
The aim of the study is to analyze contemporary management systems and knowledge sharing, based on the analysis of existing materials and qualitative research - case studies. First it was necessary to solve dictionary concerns. In many languages, the words cooperation and collaboration are usually used as synonyms, and in some countries, collaborations are often pejoratively associated, so it is necessary to analyze the existing materials and present an adequate and precise definition of the title concepts. Then, the authors focused on a practical approach to working with intellectual capital throughout the organization and presented examples that can serve as role models.
\end{abstract}

\section{What is knowledge?}

Nowadays, knowledge is not just one of the main resources of organizations or enterprises, but it is also fundamental to their success. It is indispensable when determining the strategic elements of the management system such as: mission, vision, goals, plans and strategies. Encyclopedias define knowledge as a "resource of information from a given field" [1], or: "all information obtained by learning, familiarity or awareness of something" [2]. There are four levels of nonmaterial knowledge resources in the literature. Knowledge is in the middle, between information and wisdom. The lowest level is data, namely particular signs, facts, figures, certain details related to a particular event. Data is information, when it is adequately selected, compared, processed and properly interpreted and evaluated. Information is a stream of news, and widespread information becomes the knowledge that can be afterwards utilized in an organization. For the information to be transformed into knowledge, it must be up-to-date, comprehensible for the recipient, legible, precise, easy to use, related to presence, directed towards the future, and it must come from a reliable and proven source. The highest level is wisdom [3].Definitions of wisdom suggest that it is highly personified and strictly related to a human factor. It can therefore be states that these are the people - not the enterprise - that pose the main carrier of the knowledge resource [4]. P.F. Drucker, believed to be "the father" of contemporary methods of management put it in this way: "people should not be managed; the managers' task is to lead the people, the goal is to derive efficiency from the knowledge and strengths of each employee" [5].

\subsection{Knowledge Service and Knowledge Management - what it is?}

It should be noted that there are some tools for knowledge management and cooperation in organizations. For this purpose, a combined form of two approaches is adopted, which have had its place in management for a longer time now, and they are currently getting on popularity, namely Knowledge Management (KM) and Knowledge Service (KS). There is a need to combine these two approaches, because the KM itself sometimes seems to be too distant and unrelated to the factual actions undertaken in a workplace, and there are plenty of persons who does not understand the term "knowledge management" correctly.

Knowledge Service, as a single management methodology combines the basic principles of knowledge management, information management and strategic learning. The combined links form a common structure which ensures the added value from cooperation and the knowledge-sharing process. In other words, if we share what we know, we work not only better but also smarter, similarly to employees and co-workers that we cooperate with. KS makes all employees involved in knowledge sharing, not only in ordinary units focused on knowledge (research management, etc.). All functional units develop, share and use the knowledge, and thanks to KS as a practical

\footnotetext{
* Corresponding author: mduvall@afm.edu.pl
} 
methodology of dealing with information, knowledge and learning, they create high efficiency and effectiveness in each business unit, and the results bring benefits to an entire larger company [6].

According to NASA, Knowledge Management (KM) is nothing else than "providing proper knowledge to proper people in proper time, and helping in developing this knowledge, sharing it and making decisions based on this knowledge in such a way as to achieve some measurable results". "Knowledge management is a process of constant implementation of management functions focused on the knowledge-derivative resources (internal and external, existing and non-existing, disclosed and undisclosed) and on tasks and instruments for organization and communication" [7].

As a rule, the knowledge resources in organizations are unstructured, difficult to located or search. Therefore, those willing to act based on the knowledge apply a cyclical management process consisting of the following stages: discovering the knowledge, generating the knowledge, disseminating the knowledge, using the knowledge, preserving the necessary knowledge [8]. When the organization's goal related to information, knowledge and learning is clearly specified, the search for ways to develop, share and use the knowledge becomes almost natural. What follows is that it is quite simple to determine this goal: an organization wants the knowledge development (KD) / knowledge sharing (KS) / knowledge using (KU) process to be as good as possible [9].

Proper knowledge management helps co-workers and organizations to cooperate by:

- Providing all members of the organization with a platform for sharing ideas, acquiring valuable feedback and being a part of the discussion;

- Notifying the users as soon as new information or changes appear;

- Encouraging to participation in the organization through gamification, using such elements as badges and prizes which consider the contribution of particular employees;

- Developing an easy-to-use database of topics, ideas and documents to help employees find the information they need to contribute to the conversation;

- Distributing individual knowledge in the whole organization;

- Discovering previously unused and valuable knowledge resources in an organization;

- Enabling interviews with field experts that do not disrupt the daily workflow [10].

\section{Cooperation and collaboration - how do they differ?}

Success of an entire organization or a single undertaking comes when people cooperate, share what they know, either the knowledge about a current project or everyday information used for mundane actions. In all cases the employee must have access to what they need, and if they do not have this access, they must know who to ask for help. Such an approach should be an integral part of a contemporary functional structure for companies and organizations; nobody should work alone, cooperation with others is the key - wee need other people, their skills and knowledge they have, and they need us [11]. It is even more justified that if we take a closer look at the research and experience of public, private, governmental, industrial, academic or professional organizations, we will see that it is becoming increasingly more difficult to implement ideas and projects alone.

In many languages the words cooperation and collaboration are usually used as synonyms, and additionally collaboration has some pejorative associations for many, so it is necessary to analyze the existing materials (mainly foreign) and present an adequate and precise definition of the terms in question. Of course, generally speaking, both cooperation and collaboration involve a group of people who work together to reach a common goal. The key difference between them is that while cooperation combines individual efforts of all team members, those who collaborate implement the project together in order to reach the goal, meaning they work as equals, usually without a leader, so they can develop ideas or make a decision. While cooperation is usually supervised by a team leader, and persons in a team are delegated to particular tasks that should be performed to contribute to reaching the ultimate goal of the team.

K.A. Bruffee in his 1995 article "Sharing Our Toys: The "Cooperative Learning Versus Collaborative Learning" already pointed to important differences between collaboration and cooperation. Collaboration refers to relationships between partners, where each entity learns from the parents and thus pursues their own objectives more effectively. Particular entities that collaborate with each other remain autonomic; the relations between them may be broken at any time, and this has no impact on implementation of the goals by particular entities. The term cooperation is defined differently - it occurs when entities work together in order to reach a given common goal. In the case of such relations no entity may effectively operate without constant support of other cooperating entities [12].

The research carried out at Stanford University suggested, among other things, a higher level of involvement and success and a lower level of fatigue in collaborative teams - the condition for success of collaboration is to have perfect interpersonal skills, because it is crucial that each involved persons brings their ideas, opinions and knowledge. In turn, cooperation, thanks to an adequate leader may help in reaching the goal in a more effective way (faster), distributing the burden equally and allocating the tasks to the persons of the most appropriate set of skills; it can help the employees feel more engaged and motivated.

It should be recognized that nowadays a key concept is to motivate to participation in a collective process of knowledge development by supporting various circles and groups of works in team works and by collecting the value of this work. Regardless of whether the knowledge management will be based on cooperation or collaboration, they will bring some measurable effects. Organizational culture is crucial in this scope, including the system of patterns of 
thinking and acting, which are established in the social environment of the organization and important for the implementation of its formal goals. According to the Encyclopedia of Management, the organizational culture is the social standards and systems of value that stimulate the workers, a proper organizational climate, the way of management, shared meanings and symbols, cognitive schemes, requirements of behavior. These are all fundamental assumptions, which were made up, discovered or created by a given group, while learning to adapt to the environment and integrate internally [13].

\section{NASA "REAL Knowledge Services" - case study}

The concept of knowledge management is characterized by quite a large diversification. There is no single recognized way of understanding the subject of management which knowledge is. The approaches to the essence of knowledge management are also different. Thus, it seems justified to take a closer look at a selected example of a proven system, which may and even should be regarded as exemplary.

Such an example is the system used in the National Agency for Astronautics and Space (NASA). This is a model deriving from experience in developing the Knowledge Services. It encompasses the organizational perspective of the knowledge management system, which corresponds well to rapid change and accelerates the acquisition of knowledge (science) in comprehensive projects environments that are rich in data.

Over thirty years of NASA's experience suggests that effectiveness can be improved significantly if we focus on capturing and communicating the project knowledge among functional units of an organization, individual employees, project teams. It must be noted that in the case of NASA, the knowledge covers some unique requirements, solutions and knowledge shared among persons, teams, projects, programs, directorates of missions and centers. It is often referred to as codified and specialist knowledge (scientific, engineering, technical and business knowledge). It is equally important not to forget that there are also other significant types of knowledge, which play an important role, for example in the public context. This includes, among other things, the perception of the organizational strength and relations in interpersonal and team environments, and the way which optimum balance of those features influences the social relationships. Better understanding of the social context of knowledge in every project may serve as the basis to improve the priorities and adopt a more pragmatic approach to problem solving. Strong motivation regarding knowledge acquisition in such an organization as NASA ultimately serves the success of space missions. The complexity of the undertakings forces to a quick response to any changes and impacts the whole organization, its internal social, technical, strategic and administration systems [14].

A strategic perspective of the knowledge management system is necessary to determine and define the objectives o of projects and risks related to knowledge resources (or lack thereof). In the case of NASA, the key requirements related to the intellectual capital and adequate tools had been developed for years. It is worth noting that they resulted from unpleasant experiences which were known to the public domain (among others the Challenger disaster in 1986, the failure of the Martian mission in 1998-99, the Columbia disaster in 2003). The ongoing investigations changed the Agency's paradigm, making it necessary to focus not only on the individual capabilities of team members, but also on a team as a whole. New guidelines were developed in order to prevent any operational errors; the approach to crew safety was tightened up which required inclusion of better and broader scientific research. Additionally, after the Columbia disaster in 2003, the investigation revealed that mission leaders had made erroneous assumptions about the strength of the materials and that the processes of information flow, communication and dynamics of interpersonal contacts in the team had been ineffective. The knowledge derived from these experiences forced NASA to introduce some significant changes, among other things, to establish a multidisciplinary knowledge-exchange forum and changes in management and policy of the Agency. In 2011, the NASA Air Safety Advisory Panel (ASAP) indicated in its report that the Agency should develop a more systematic approach to capturing and collecting open and undisclosed intellectual capital and recommended the formal appointment of a Chief Knowledge Officer (CKO) to be supported by a team of designated CKOs in each directorate, center, and mission [15].

Each knowledge management model in NASA must be flexible enough to meet various requirements and correspond to the organizational culture characteristic for each center, mission directorate, etc. Thus the model adopted in the Agency should be determined as a federation model. CKO NASA may be a mediator and the highest expert in the agency's knowledge management, but they are not to play a role of a supervisor or a direct superior to CKO of particular functional parts of the Agency. Therefore, the balance has been achieved between autonomy and responsibility, where centers, mission directorates and functional offices can freely define their approach to knowledge, so it suits their particular needs best, and at the same time they are responsible for knowledge sharing, so it brings the benefits for the whole organization. New NASA policy, by developing integrated KS, allowed knowledge resources management in a way enabling the Agency to implement its tasks: programs, projects and missions with the highest probability of success [16].

One of the NASA's strategic imperatives is the use of the Accelerated Learning (AC) tactics which consists in parallel use of cutting-edge digital technologies and traditional knowledge sharing activities. AC involves modern learning strategies, new information and communication technologies (e.g. social media) and it is open to multidisciplinarity of knowledge and crossing of disciplines - but the essence is the broadest possible look on the learning process which exerts positive impact on the organization's effectiveness. The operational processes are strictly 
related to the crucial internal and external knowledge sources, which are to meet the expectations of the organization, i.e. optimization of searching for, searching through and adjusting the knowledge [17].

NASA Knowledge Community has identified a starter set of knowledge categories that apply to most of the Agency's activities. This is how a knowledge map with the following categories was established: (1) online tools, (2) search, taxonomy and tagging tools, (3) case studies and publications, (4) lessons learned and process issues related to the collection, sharing and acquisition of knowledge, (5) knowledge network, (6) social and interpersonal relationships. Thanks to this map the Agency can combine all identified tasks, projects, etc. with the map, and create active links to the resources [18].

CKO NASA office has developed the Rapid Engagement through Accelerated Learning (REAL) model to promote opportunities for more comprehensive and accurate problem definition; encourage pragmatic targeting which ensures better decision-making; and to help solve problems arising from individual features of employees (prejudices, personal goals, conflicting interests). The core of the REAL model is the KM operational cycles - discovery, capture, and sharing of knowledge, but this is also where the effectiveness of knowledge-based activities is measured. For example: capturing knowledge is an activity and a behavior is a measure; knowledge-sharing is an activity and its use is a measure; discovery is an activity and development of results is a measure.

Phases/stages, which in the REAL model are intended to serve the increase in the activity of the organization's intellectual capital, are as follows: (1) challenges / opportunities are selected and prioritized, (2) a learning plan is developed which supplements a project charter and a project plan, (3) functional communities of practitioners are recruited and the contact points are identified, (4) the basic KM operational cycle is supported by particular strategies of learning, methods, models and technological tools, (5) individual and team knowledge is expanded, supported and reinforced by KS activities, (6) expectations of the external environment in the scope of organization's actions and the impact on the society are identified and operationalized into objective definitions of efficiency in time and space, (7) activities and results of the projects regarding the innovative achievements and organizational improvement are carried out in the "closeout" mode in order to capture and preserve the experiences with a purpose of using them in the next projects. Another important aspect of the REAL model is what NASA calls " $4 \mathrm{~A}$ ": ability, attitude, assignments, and alliances [19].

REAL Knowledge Services, through continuous development and establishment of a community of practitioners who are aware of the significance of knowledge and who understand the processes of knowledge transfer both inside and outside the organization, serve to promote excellence both in project management and in engineering. Through simplification and integration of KS in the whole Agency - thanks to talks, discussion forums, conference, publications, research and digital tools, the CKO NASA office gathers experiences, skills and knowledge, and the constantly growing resources are easily searchable and adaptable. It is also worth mentioning that the network created by CKO goes far beyond NASA itself and includes experts from various industry sectors, scientists from numerous disciplines, other governmental agencies, research and professional organizations as well as international space agencies.

\section{Conclusion}

Nowadays, all environments of cooperation - working groups, communities of practitioners, networks of cooperating enterprises and organizations - are based on knowledge, and there is some strong dependence between cooperation and knowledge management (KM). In today's global economy, strongly influenced by information technologies, the contemporary organizations must face new challenges by adopting their strategies and restructuring their operation to suit new requirements of the 21 st century economy - the economy of knowledge. While management is a process of developing value from the intellectual capital and sharing the knowledge with others who need this capital, and this means that two processes are important here: (1) development and storage of knowledge and (2) knowledge sharing and distribution process.

Therefore, there is a need to take the broadest possible perspective on the organizational "learning" process, and take care that the gathered experiences, skills and knowledge which make up the constantly growing resources, are easily searchable and adaptable. Second of all, there is a need to remember that each knowledge management model must be flexible enough to meet various requirements and address the organizational culture. Third of all, a key role is played by all activities that motivate the employees to participate in a collective process of knowledge development. Therefore and fourth of all, we need to realize that the true power of an organization is in its employees, regardless of their experience or position in the company, who in majority have the potential to contribute to the strategy, tactics and new possibilities. Fifth of all, to make the above possible, an organization needs to preserve the balance between autonomy and responsibility, taking account of the fact that low control from management and higher autonomy provide a possibility for unconventional and creative thinking, and this leads to greater innovation - a horizontal management structure serves the culture of openness and sharing of ideas and opinions. Sixth of all, the contemporary leaders should understand that organizational effectiveness can be improved significantly if attention is focused on capturing and transferring the knowledge among functional units in an organization, individual employees, project teams. Seventh of all, we cannot forget about the social context of knowledge, this a lot of attention must be paid to information flow processes, communication and dynamics of interpersonal contexts in a team. 


\section{References}

1. Encyklopedia Popularna PWN. Warszawa, p. 849 (1982).

2. M. Szymczak, Słownik języka polskiego, Warszawa, p. 700, (1981).

3. E. Karaś, A Piasecka - Głuszak, Zarządzanie wiedza - dlaczego tak ważne?, Nauki o Zarz. 4 (17), p. 47, (2013).

4. M. Kłak, Zarządzanie wiedza we współczesnym przedsiębiorstwie, Kielce, p. 18, (2010).

5. P.F Drucker, Zarzadzanie XXI wieku - wyzwania, Warszawa, p. 30-31, (2009).

6. G. S. Clair, Eight Things You Need to Know About Knowledge Services, https://www.smrknowledge.com/working-together-collaboration-and-knowledge-services/ (2017).

7. K. Perechuda, Zarzadzanie wiedza w przedsiębiorstwie, Warszawa, p. 219, (2005).

8. E. Karaś, A Piasecka - Głuszak, Zarządzanie wiedza - dlaczego tak ważne?, Nauki o Zarz. 4 (17), p. 51, (2013).

9. G.S. Clair, Eight Things You Need to Know About Knowledge Services, https://www.smrknowledge.com/working-together-collaboration-and-knowledge-services/ (2017).

10. Ch. Smith, 7 Ways Knowledge Management Drives Enterprise Collaboration, http://www.dzonesoftware.com/blog/7-ways-knowledge-management-drives-enterprise-collaboration (2018).

11. G.S. Clair,Eight Things You Need to Know About Knowledge Services, https://www.smrknowledge.com/working-together-collaboration-and-knowledge-services/ (2017).

12. K.A. Bruffee, Sharing Our Toys: Cooperative Learning Versus Collaborative Learning, Change: The Mag. of High. Learn., Vol. 27, p. 12-18, (1995).

13. Encyklopedia zarządzania, https://mfiles.pl/pl/index.php/Kultura_organizacyjna (2018).

14. E. Hoffman, J. Boyle, R.E.A.L. Knowledge at NASA, Pennsylvania, https://www.pmi.org//media/pmi/documents/public/pdf/white-papers/real-knowledge-nasa.pdf (2015).

15. Ibid.

16. Ibid.

17. Ibid.

18. Ibid.

19. Ibid.

20. M. I. Muntean, D. Târnăveanu, Some Considerations About Collaborative Systems Supporting Knowledge Management in Organizations, WSEAS Trans. on Comp. Issue 8, Vol. 8, p. 1378, (2009). 